\title{
Differential Bird Responses to Colour Morphs of an Aposematic Leaf Beetle may Affect Variation in Morph Frequencies in Polymorphic Prey Populations
}

\author{
Lucia Doktorovová ${ }^{1}$ Alice Exnerová ${ }^{1}$ Kateřina Hotová Svádová ${ }^{1}$ Pavel Štys ${ }^{1}$. Dana Adamová-Ježová ${ }^{1}$. \\ Vitali Zverev ${ }^{2} \cdot$ Mikhail V. Kozlov $^{2} \cdot$ Elena L. Zvereva² ${ }^{\mathbb{B}}$
}

Received: 21 June 2018 / Accepted: 19 November 2018 / Published online: 27 November 2018

(c) The Author(s) 2018

\begin{abstract}
The selection of prey by predators should, theoretically, favour uniformity in the warning signals displayed by unpalatable prey. Nevertheless, some aposematically coloured species are polymorphic. We tested the hypothesis that colour morphs of unpalatable prey differ in the efficacy of their aposematic signal for birds, thereby affecting the selective advantages of these morphs. We used colour morphs (red-and-black light, red-and-black dark and metallic) of the chemically defended leaf beetle Chrysomela lapponica. In laboratory experiments, naïve great tits (Parus major) attacked live beetles of all colour morphs at the same rate. By contrast, wild-caught tits attacked light beetles at first encounter at the same rate as a novel control prey, but significantly avoided both dark and metallic beetles. Beetles of all colour morphs were similarly unpalatable for birds, and about half of the attacked beetles were released unharmed. Avoidance learning was similarly fast for all three leaf beetle morphs. However, in the next-day memory test, the dark beetles were attacked at a greater rate than beetles of two other morphs, indicating their lower memorability. A field experiment suggests that at low C. lapponica population densities, dark beetles have a survival advantage over light beetles, potentially due to the lesser conspicuousness of the dark pattern; however, when the density is high, dark beetles lose this advantage due to the low memorability of their pattern. Thus, the direction of selective bird predation on prey colour morphs may depend on prey density and thereby contribute to temporal shifts in colour morph frequencies following population fluctuations.
\end{abstract}

Keywords Avoidance learning $\cdot$ Colour polymorphism $\cdot$ Density dependence $\cdot$ Parus major $\cdot$ Population dynamics · Selective predation

\section{Introduction}

Conspicuous colouration in unpalatable or noxious animals acts as a warning signal of their unprofitability, a phenomenon known as aposematism. Both theoretical expectations (Servedio 2000; Endler and Mappes 2004) and empirical

Electronic supplementary material The online version of this article (https://doi.org/10.1007/s11692-018-9465-8) contains supplementary material, which is available to authorized users.

Elena L. Zvereva

elezve@utu.fi

1 Department of Zoology, Charles University, Prague, Czech Republic

2 Department of Biology, University of Turku, 20014 Turku, Finland studies (Mallet and Joron 1999; Chouteau et al. 2016) point to a positive frequency-dependent (antiapostatic) selection of aposematic prey. A more common warning display is recognised more easily by the predators, so avoidance learning is faster. This results in a higher survival of prey with a more frequent form of a warning signal (Joron and Mallet 1998; Beatty et al. 2004), i.e. the fitness of a phenotype increases with its frequency. This process is responsible for the observed convergence between chemically defended aposematic species that form mimicry assemblages (Sherratt 2008; Chouteau et al. 2016), as well as for intra-specific monomorphism in warning signalling (Ruxton et al. 2004; Borer et al. 2010). However, contrary to theoretical predictions, many organisms possess variable warning signals, and intra-population variation in aposematic pattern is a frequent phenomenon in a wide range of taxa: insects, for example the hibiscus harlequin bug (Tectocoris diophthalmus; Fabricant 
et al. 2014), the alpine leaf beetle (Oreina gloriosa; Borer et al. 2010) and the wood tiger moth (Parasemia plantaginis; Hegna et al. 2013); amphibians, for example the dyeing poison frog (Dendrobates tinctorius; Rojas and Endler 2013); and reptiles, for example vipers (Vipera berus and V. aspis; Broennimann et al. 2014)

Several mechanisms are capable of maintaining the within-population polymorphism of colour patterns (Mallet and Joron 1999; Gordon et al. 2015). Of particular importance is negative frequency-dependent (apostatic) selection, in which predators consume disproportionally more of a particular prey when it is common and less of that prey when it is rare (reviewed by Punzalan et al. 2005). Several studies have provided evidence for apostatic selection, but most have examined repeated encounters with palatable prey. In these situations, predator develops a search image, which increases the probability of detecting that prey type (Dukas 2002; Punzalan et al. 2005). This scenario differs from the situation in which the prey advertises its toxicity or unpalatability by its conspicuous warning coloration. Encounters with unpalatable aposematic prey result in avoidance learning in the predators and lead to a positive frequencydependent (antiapostatic) selection that affects the evolution of coloration in aposematic prey species (Borer et al. 2010; Chouteau et al. 2016).

The directions of selection on prey may change if different predators vary in their responses to a particular aposematic signal (Endler and Mappes 2004; Lindstedt et al. 2011; Nokelainen et al. 2014). The efficacy of warning displays is influenced by their conspicuousness (Endler and Mappes 2004; Guilford 1986; Gamberale-Stille 2001; Prudic et al. 2007), which depends on the context (background, illumination, distance) and pattern traits, such as colour, internal contrast, size and symmetry of the pattern elements (Forsman and Merilaita 1999; Lindstedt et al. 2008; Aronsson and Gamberale-Stille 2013). For example, some aposematic patterns are conspicuous at a close distance and become cryptic with increasing distance or against another background (Tullberg et al. 2005; Gamberale-Stille et al. 2009; Barnett et al. 2017). Colour morphs within populations of aposematic prey may differ in traits that affect their conspicuousness, and this variation may lead to interplay between positive and negative frequency-dependent selection by predators. In this way, a polymorphic prey population may escape from positive frequency-dependent selection. However, only a few studies (Lindstedt et al. 2011, 2016; Hegna et al. 2013; Nokelainen et al. 2014) have explicitly addressed the role of visually hunting predators in the maintenance of polymorphism within populations of aposematic prey. Prediction of the selective advantages of different morphs in natural populations of defended prey requires exploration of whether coexisting aposematic displays differ in their ability to elicit unlearned wariness in potential predators, accelerate the rate of avoidance learning and strengthen the memory of aversive experience with the prey.

Many leaf beetle species exhibit within-population polymorphism in their colour pattern (Mikhailov 2001; Nahrung and Allen 2005). The Lapland leaf beetle, Chrysomela lapponica, is chemically defended (Pasteels et al. 1989) and highly polymorphic in the coloration of its elytra, which varies from entirely red through various red-and-black patterns, to an entirely black or metallic colour (Milyashevich 2000; Mikhailov 2001); all these patterns can be considered as warning signals advertising the beetle's unpalatability to predators. The intra-population polymorphism of $C$. lapponica differs considerably between geographic populations (Milyashevich 2000; Mikhailov 2001; Gross et al. 2004); for example, the proportion of the completely black (metallic) morph varies from zero in Fennoscandian populations (Gross et al. 2004; Zvereva et al. 2002) to $86 \%$ in the Yekaterinburg population (Y. Mikhailov, personal communication) and to $100 \%$ in the Belarusian population (Milyashevich 2000).

The existence and maintenance of dark (melanic) morphs in some populations may reflect thermoregulatory benefits of dark morphs at low temperatures (Clusella-Trullas et al. 2008). This prediction is confirmed by an increase in the proportion of melanic individuals of some species with latitude and altitude (Clusella-Trullas et al. 2008; Hegna et al. 2013) and by the concomitant decrease in the proportion of melanic morphs in populations with climate warming (Brakefield and de Jong 2011; Zeuss et al. 2014). In $C$. lapponica, dark males copulate more frequently than light males at low temperatures due to their superior thermal capacity, which allows them to move faster (Zverev et al. 2018). However, the proportion of black or metallic morphs in $C$. lapponica does not depend on the latitude or altitude of the locality: it may be high in southern low-altitude populations and low in northern and high-altitude populations (Mikhailov 2001). Thus, factors other than a thermal melanism are likely to contribute to the observed geographic variation in polymorphism of $C$. lapponica.

The proportions of different morphs in a population may also vary among years (Svensson and Abbott 2005; Wang et al. 2009). In particular, the proportions of dark morphs in C. lapponica populations depend on the beetle population density and stage of population cycle (Zvereva et al. 2002). These among-year variations were explained by the selective mortality of colour morphs due to density-dependent changes in plant quality (Zvereva et al. 2002), but densitydependent selective predation by visually hunting predators can also contribute to the observed variation. However, this contribution cannot be estimated yet, because the responses of avian predators to different colour morphs of $C$. lapponica beetles have not been studied. The extensive knowledge of the life history and population ecology of $C$. lapponica 
(Gross et al. 2004; Zvereva et al. 2002; Zverev et al. 2018) makes this species an excellent model for studies on the role of predators in the maintenance of colour polymorphism and in determining the variations in morph frequencies in aposematic prey populations.

In this study, we tested the hypothesis that avian predators respond differently to different colour morphs of aposematic prey co-existing within the same population, thereby potentially affecting the selective advantages of these morphs irrespectively of their frequencies. We studied the bird behavioural responses, namely initial wariness, avoidance learning and memory, to three colour morphs of $C$. lapponica and the ability of birds to generalise between the different colour morphs in the experiments with both wild-caught and handreared great tits, Parus major. We then linked the observed differences in great tit behaviour with the survival of different $C$. lapponica morphs in nature by estimating the intensity of bird attacks on leaf beetles in field experiments. We also determined whether selective bird predation depends on beetle population density by conducting field experiments in localities where this leaf beetle was common and where it was absent.

\section{Materials and Methods}

\section{Prey and Predator}

\section{Leaf Beetle Chrysomela lapponica}

Chrysomela lapponica (Chrysomelidae) is a medium-sized (5-8 $\mathrm{mm}$ long) leaf beetle widely distributed in Palaearctic. Geographic populations of this leaf beetle differ in their host-plant specialisation, but all populations used in this study were willow-feeding to control for potential effects of host plants on beetle chemical defences. Adults emerge in late summer, feed for a couple of weeks, hibernate in soil and start feeding and copulating on willows at the time of the next leaf flush. Larvae feed on willow foliage from early July to early August and pupate on the leaves.

Like other species of the subtribe Chrysomelina, both larvae and adults of $C$. lapponica are defended against natural enemies by toxic and/or deterrent chemicals, which differ in larvae and adults (Pasteels et al. 1984). Adults synthesise de novo isoxazolinone derivatives that are released from pronotal and elytral exocrine glands upon disturbance (Pasteels et al. 1989; Sugeno and Matsuda 2002) and act as a defence against predators (Pauls et al. 2016). Beetle unpalatability is advertised by two different types of aposematic coloration: a red-and-black pattern or a metallic black with blue iridescence (Fig. 1). Preliminary analysis indicates that the colour morphs of $C$. lapponica do not differ in the nature of their defensive chemistry (M. Hilker, personal communication).
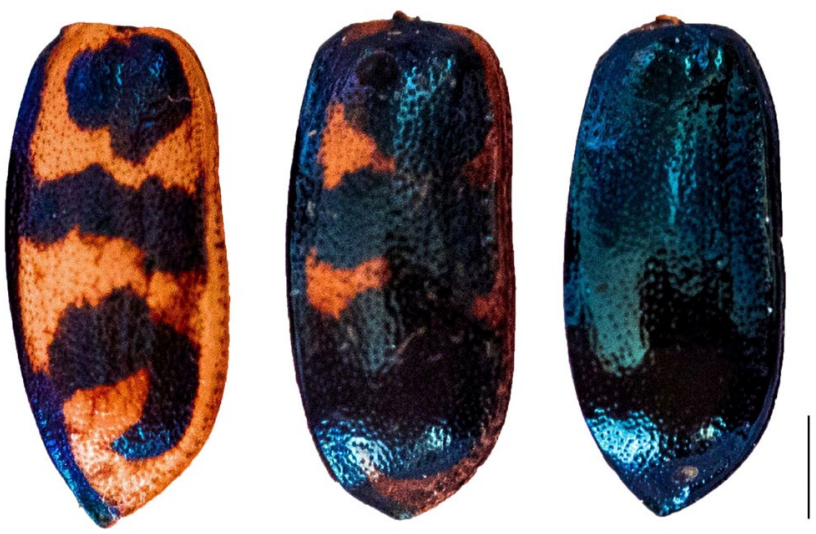

Fig. 1 Right elytra of three colour morphs of Chrysomela lapponica used in the study. From left to right: patterned light, patterned dark and metallic morphs. Scale: $1 \mathrm{~mm}$

In this study, we used beetles from three populations differing in within-population polymorphism. The population from Monchegorsk $\left(67^{\circ} 58^{\prime} 45^{\prime \prime} \mathrm{N}, 32^{\circ} 58^{\prime} 52^{\prime \prime} \mathrm{E}\right.$; hereafter, the Kola population) includes patterned light and dark morphs, with the dark beetles representing $5-40 \%$ of all individuals (Zverev et al. 2018). The populations from Yekaterinburg $\left(56^{\circ} 45^{\prime} 55^{\prime \prime} \mathrm{N}\right.$, $60^{\circ} 39^{\prime} 19^{\prime \prime} \mathrm{E}$; Siberia population hereafter) and Medvezhjegorsk $\left(63^{\circ} 00^{\prime} 07^{\prime \prime} \mathrm{N}, 34^{\circ} 22^{\prime} 55^{\prime \prime} \mathrm{E}\right.$; Karelia population hereafter) contain the typical patterned morph (corresponding to the light morphs from Kola population) and the metallic black morph; the latter accounts for ca. $80 \%$ in the Siberia population and ca. $30 \%$ in the Karelia population. Crossing experiments demonstrated that the colour patterns in C. lapponica are genetically based (Zverev et al. 2018, and unpublished).

The beetles used in our experiments were reared in the laboratory from larvae collected in July 2015 and June 2016. They were fed with their native host plants (Salix myrsinifolia for Kola and Karelia populations and S. caprea for Siberia population) until pupation. The hatched beetles were then fed with the same host plants until they discontinued feeding and were subsequently kept in vials lined with moist paper at $5{ }^{\circ} \mathrm{C}$ until the experiments. Dark and light morphs of red-andblack patterned beetles from Kola population were further distinguished based on the proportion of black coloration on the elytra ( $>85 \%$ and $<70 \%$, respectively), as described by Zverev et al. (2018); we did not use intermediately coloured individuals (about $5 \%$ of all beetles) in our experiments. EZ performed the classification of all beetles. We used live beetles in the laboratory experiments with great tits; for field experiments, the beetles were killed by freezing.

\section{Great Tit (Parus major)}

Great tits are insectivorous passerines that are widely distributed across Palaearctic over a range of woodland habitats 
(Cramp and Perrins 1993). Great tits live in the same habitats as $C$. lapponica, so they are likely to encounter these leaf beetles in nature.

Adult birds were caught using mist nets in Prague $\left(50^{\circ} 04^{\prime} 48^{\prime \prime} \mathrm{N}, 14^{\circ} 14^{\prime} 24^{\prime \prime} \mathrm{E}\right)$ during September and October 2015. All wild-caught birds were at least 4 months old, and a sample contained a balanced proportion of yearlings and older individuals. The wild-caught birds were experienced with various prey types from the wild including, potentially, noxious and aposematic prey. The birds were kept separately for 2-5 days before the experiment in indoor cages $(50 \times 40 \times 50 \mathrm{~cm})$ for habituation to the laboratory environment. The cage illumination simulated daylight, and photoperiod was set according to outdoor conditions. The birds' diet consisted of mealworms (larvae of Tenebrio molitor), sunflower seeds and a commercial food mixture (Uni patee, Orlux).

Juveniles were obtained from nest boxes placed in woods at the outskirts of Prague in spring 2016. We took birds at the age of 12-15 days, when they were naïve with respect to any kind of unpalatable prey. Birds were hand-reared until they were able to feed independently. Their diet consisted of mealworms and a commercial mixture for hand-rearing the passerines (Handmix, Orlux). Nestlings were kept in artificial nest boxes in small groups. After fledging, they were housed and fed in the same way as adult birds. Experiments with juveniles started after the 35th day of their life, when they were fully independent.

\section{Experimental Design}

\section{Facilities Used in Experiments with Caged Birds}

Experiments were conducted at the Faculty of Science, Charles University, Prague. The experiments with wildcaught birds were conducted during September-October 2015, and experiments with naïve, hand-reared birds during July 2016. We tested the birds individually in wooden cages $(70 \times 70 \times 70 \mathrm{~cm})$ with wire mesh walls, equipped with a perch, a dish with water and a rotating feeding tray. The cage was illuminated by a daylight-simulating Biolux Combi 18-W bulb (Osram). The tested prey was offered to the birds in a glass Petri dish (50 $\mathrm{mm}$ in diameter) placed on the rotating tray. Before the experiment, the birds were habituated to the experimental cages, were trained to take food from a glass Petri dish placed on a rotating tray, and were deprived of food for $2 \mathrm{~h}$. Prey items were offered on a green background made from a leaf (white beam Sorbus aria in 2015, goat willow $S$. caprea in 2016). We observed the birds through a one way glass in the front wall of the cage. We recorded all experiments with a video camera and continuously noted the behavioural elements using Observer XT 8.0 (Noldus).

\section{Experiments with Wild-Caught Adult Great Tits}

The birds (63 in total) were divided into three experimental groups: 20 birds were tested with beetles of light morph, 22 birds with dark morph and 21 birds with metallic morph. We used the nymphs of Jamaican field crickets (Gryllus assimilis) as a control palatable prey that would be unfamiliar to the birds to account for the effects of prey novelty on bird responses.

An avoidance-learning session consisted of a series of trials conducted immediately one after another. We defined a trial as offering our target prey (i.e. a beetle of a particular colour morph) to the bird. Each trial was preceded by offering a control prey with the aim of controlling the bird's foraging motivation. The trial was terminated after the bird consumed the prey; otherwise, it lasted $5 \mathrm{~min}$.

If the bird did not attack the beetle during the first trial (first-offer trial hereafter), we continued the trials (i.e. offered another cricket and another beetle) until the beetle was attacked. If the bird did not attack the beetle after 20 trials, this bird was excluded from the avoidance-learning session and, subsequently, from the memory test.

The trial in which the bird attacked the beetle was recorded as the first trial of the avoidance-learning session. After this trial, we continued offering crickets and beetles, in turn, with up to three trials with each prey.

The day after the avoidance-learning session, we checked whether the birds remembered their experience with a particular prey. This memory test consisted of one trial: after the bird consumed a cricket, it was offered a beetle of the same morph as had been offered on the previous day.

The generalisation test was carried out immediately after the memory test. After the bird consumed a cricket, we simultaneously offered the bird two beetles of two different morphs that had not been used in the avoidance-learning session and the memory test. The beetles were placed in two separate Petri dishes on a rotating tray, and the trial lasted a maximum of $10 \mathrm{~min}$.

During each trial we recorded: (1) the number of approaches to prey and time spent for close prey inspection before making the decision about the attack or retreat; (2) the time from the beginning of the first-offer trial to the first attack on prey (first-attack latency hereafter); (3) whether prey items were attacked (touched, pecked or seized), killed and eaten by birds; and (4) the duration of discomfort behaviour (cleaning the bill, shaking the head, ruffling the feathers, vomiting). If, at the end of a trial, the beetle was damaged by a bird but still alive, we recorded whether it survived until the next day. If the beetle died during this time, we considered it as 'killed'.

\section{Experiment with Naïve Juvenile Great Tits}

The birds (44 in total) were divided into two experimental groups: 21 birds were tested with beetles of light and dark 
morphs, and 23 birds with light and metallic morphs. These combinations of morphs reflect the situation that occurs in natural populations with two kinds of polymorphism, in which either the metallic and the light-patterned morphs (Siberia and Karelia populations) or the dark-patterned and the light-patterned (Kola population) morphs coexist.

Experiments were conducted in the same way as the generalisation test, i.e. we used a dual-choice test. We first offered a mealworm (a familiar control palatable prey), then a cricket (a novel control palatable prey). If the bird ate the cricket, we offered it two $C$. lapponica beetles, each belonging to a different morph, and recorded which morph was attacked first. We also recorded the same behavioural elements as in the experiment with wild-caught birds. This trial lasted $10 \mathrm{~min}$

\section{Field Experiments}

Two field experiments were conducted to test whether wild birds cause different mortality in beetles with different colour patterns and whether selective predation depends on the novelty of this type of prey, which decreases with an increase in prey population density. Morphs occurring in the Kola population were tested at four sites in the Kola Peninsula. The study area is inhabited by $C$. lapponica, but its distribution is patchy and the selected sites differ considerably in the abundance of this leaf beetle (Zvereva et al. 2002). The population density of $C$. lapponica in two our sites $\left(67^{\circ} 36^{\prime} \mathrm{N}\right.$, $32^{\circ} 39^{\prime} \mathrm{E}$ and $67^{\circ} 35^{\prime} \mathrm{N}, 32^{\circ} 33^{\prime} \mathrm{E}$ ) was extremely low: no beetles were found during a 30-min survey on host plants in June of 2016 (low density sites hereafter). In two other sites $\left(67^{\circ} 48^{\prime} \mathrm{N}, 32^{\circ} 47^{\prime} \mathrm{E}\right.$ and $\left.67^{\circ} 38^{\prime} \mathrm{N}, 32^{\circ} 45^{\prime} \mathrm{E}\right)$ C. lapponica was more abundant: 6 and 8 beetles were found during a 30-min survey (high density sites hereafter). Five $S$. myrsinifolia bushes were selected at each site, and beetles from Kola population, killed by freezing and freshly defrosted, were glued with silicone to the leaves (four light and three dark beetles per plant, one beetle per leaf). The experiment ran from 11 to 29 August 2016.

Morphs occurring in the Karelia population were tested in the surroundings of Turku, at sites where C. lapponica has never been recorded and thus was a novel prey for local birds. We selected 10 bushes of $S$. caprea and attached beetles from the Karelia population in the same way as described for the Kola Peninsula (seven light patterned and three metallic beetles per plant). The experiment ran from 21 July to 2 September 2016.

In both experiments, we checked beetles at 3-5 days intervals and individually recorded the damage caused by birds as follows: 0 , no damage; 1 , beetle is decapitated, or the elytra or thorax bear visible damage; 2 , both elytra or whole beetle is missing; 3 , signs of two attacks are recorded during the observation time.

\section{Statistical Analysis}

The numbers of birds that attacked, killed or ate the prey, as well as the numbers of beetles that survived bird's attack, were compared by Fisher's exact test $(2 \times 2$ contingency tables) or by the Chi square test $(3 \times 2$ contingency tables). Attack latencies were compared between beetles and control prey by the Wilcoxon signed rank test (paired differences); unpaired differences in attack latencies between beetle colour morphs were analysed by the Wilcoxon rank sum test. The durations of different behavioural elements were compared using the Kruskal-Wallis test. In field experiments, tree-specific mean scores were calculated for each morph and compared using a paired $t$-test. All reported $P$ values are two-tailed; the calculations were performed in R 3.0.2 and SAS 9.4.

\section{Results}

\section{Reactions of Wild-Caught Adult Birds to Colour Morphs of C. Iapponica}

\section{First Reaction to Prey}

Birds that attempted an attack hesitated longer before attacking dark (Wilcoxon signed rank test: $V=30, P=0.004$ ) and metallic $(V=3, P<0.001)$ beetles than before attacking crickets, i.e. novel control prey (Fig. 2). In contrast, firstattack latencies did not differ between beetles of the light morph and crickets $(V=105, P=1)$. First-attack latencies differed between the beetle colour morphs: birds hesitated less before attacking light beetles than before attacking dark (Wilcoxon rank sum test: $W=87, P=0.0018$ ) and metallic ( $W=60, P=0.0021$ ) beetles (Fig. 2).

Beetles of the light morph were attacked in the firstoffer trial more frequently compared to beetles of dark and metallic morphs (Fig. 3a; Fisher's exact test: $P=0.0007$ and $P=0.0001$, respectively)

\section{Avoidance-Learning Session}

The numbers of birds that did not attack any beetle during 20 subsequent trials were similar for light and dark beetles ( 0 and 2 birds, respectively; Fisher's exact test: $P=0.26$ ), and greater for metallic than for light morphs ( 6 and 0 birds, respectively; $P=0.01$ ). Across all groups, $45.5 \%$ of the birds attacked a beetle only in one trial. After the first attack, the attack rates significantly decreased for all colour morphs (Fisher's exact test, light morph: $P=0.003$; dark morph: $P=0.01$; metallic morph: $P=0.04$ ). The proportion of birds that attacked the beetles in more than one trial did not differ among the morphs (frequency test: $\chi^{2}=2.82, \mathrm{df}=2$, 


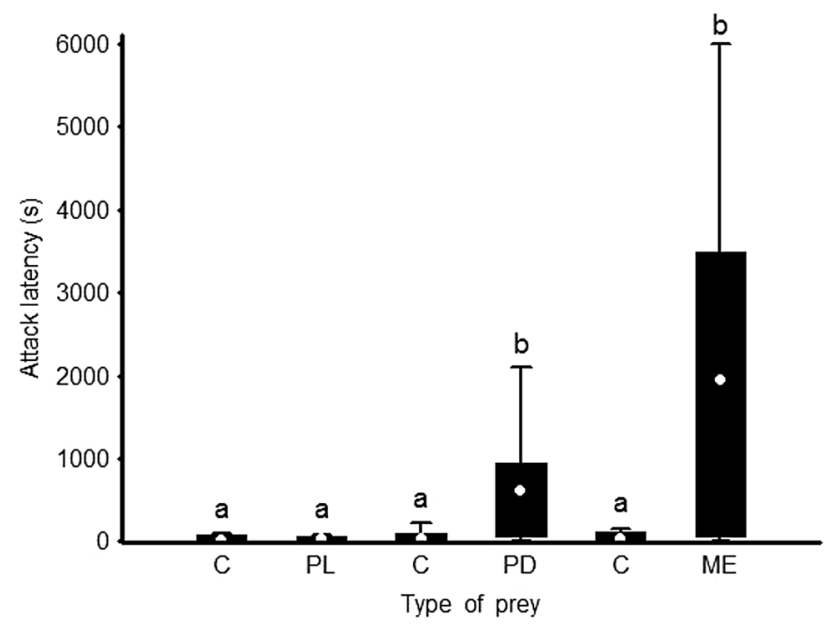

Fig. 2 First-attack latencies of wild-caught great tits tested with patterned light (PL, 20 birds), patterned dark (PD, 20 birds) and metallic (ME, 15 birds) morphs of Chrysomela lapponica, compared to a novel control prey $(\mathrm{C}$, crickets; three boxes correspond to three groups of birds tested with different beetle colour morphs). Only birds that attacked the beetle at least once were included. Pointmedian, box-lower and upper quartiles, whiskers-non-outlier range. Different letters indicate significant $(P<0.05)$ differences between prey types (paired differences: Wilcoxon signed rank test; unpaired differences: Wilcoxon rank sum test)

$P=0.24$; Fig. $3 b)$. The same numbers of birds killed and consumed beetles of all colour morphs during the avoidancelearning session (Supplementary material Table 1). The numbers of beetles that survived bird attack did not differ among colour morphs (light morph: 41.0\%; dark morph: $37.8 \%$; metallic morph: $56.5 \%$; frequency test: $\chi^{2}=1.48$, $\mathrm{df}=2, P=0.48$ ).

The number of bird approaches to the prey differed depending on the beetle colour morph (Kruskal-Wallis test: $\left.\chi^{2}=7.07, \mathrm{df}=2, P=0.03\right)$, as did the duration of close prey inspection by the bird before attack or retreat $\left(\chi^{2}=12.2\right.$, $\mathrm{df}=2, P=0.002$ ), which was longer for dark morphs than for either light $\left(\chi^{2}=5.76, \mathrm{df}=1, P=0.02\right)$ or metallic morphs $\left(\chi^{2}=11.2, \mathrm{df}=1, P=0.0008\right)$ (Supplementary material Table 2). Nevertheless, the number of attacks per bird did not differ between the beetle morphs (Supplementary material Table $2 ; \chi^{2}=1.73, \mathrm{df}=2, P=0.42$ ). The same was true for the proportions of 'negative' decisions - when the birds rejected the prey after approaching it and inspecting it from a short distance $\left(\chi^{2}=2.08, \mathrm{df}=2, P=0.35\right)$. Across all trials, the birds hesitated longer before approaching $\left(\chi^{2}=4.91\right.$, $\mathrm{df}=1, P=0.03)$ and attacking $\left(\chi^{2}=4.07, \mathrm{df}=1, P=0.04\right)$ the metallic beetles when compared to the patterned beetles (light and dark morphs combined) (Supplementary material Table 2).

After attacking a beetle, the birds spent more time cleaning their bills when compared to birds that did not attack a beetle $\left(\chi^{2}=23.4, \mathrm{df}=1, P<0.0001\right.$; Supplementary material Table 2). Only slight symptoms indicating toxic effects were observed after beetle consumption and only in three birds; this behaviour consisted of sitting briefly on a perch with their feathers ruffled, after which the birds started to behave normally again.

\section{Memory Test}

The frequencies of the bird attacks in the memory test (Fig. 3b; frequency test: $\chi^{2}=7.61, \mathrm{df}=2, P=0.022$ ) and the numbers of attacks per trial (Kruskal-Wallis test: $\chi^{2}=8.48$, $\mathrm{df}=2, P=0.01$ ) differed among the beetle morphs (Supplementary material Table 1). Fewer birds attacked beetles of the light and metallic morphs in the memory test than they did in the first-offer trial (Fisher's exact test, light morph: $P<0.001$; metallic morph: $P=0.002$; Fig. 3a, b). By contrast, birds did not appear to remember their experience with the dark morph, as the attack rates were similar for the firstoffer trial and for the memory test $(P=0.21$, Fig. 3a, b). Consequently, in the memory test, the birds attacked the dark morph more frequently than the light and metallic morphs $(P=0.003$; Fig. 3b).

\section{Generalisation Test}

Birds that learned to avoid the metallic morph attacked fewer beetles altogether in the generalisation test than did the birds that learned to avoid one of the patterned morphs (Fisher's exact test, metallic vs dark beetles: $P=0.015$; metallic vs light beetles: $P=0.026$; Fig. 4). Birds that previously attacked patterned morphs (either light or dark) attacked the metallic morph more frequently than did birds that had previous experience with the metallic morph itself $(P=0.04)$. This effect was not symmetrical: birds that had experience with the metallic morph subsequently avoided both patterned morphs at the same rate as they avoided the metallic morph ( $P=1$; Fig. 4$)$.

\section{Reactions of Naïve Juvenile Birds to Colour Morphs of C. Iapponica}

The attack latencies did not differ between novel and familiar control prey (crickets and mealworms, respectively; Wilcoxon signed rank test: $V=115, P=0.11$; Fig. 5), indicating a low degree of neophobia. Moreover, the attack latencies did not differ between beetles and crickets either in birds choosing between dark and light beetles $(V=35.5, P=0.23)$ or in those choosing between metallic and light beetles $(V=56, P=0.07)$ (Fig. 5). The first attack latencies did not differ either between light and dark morphs (Wilcoxon rank sum test: $W=13.5, P=0.65)$ or between light and metallic morphs ( $W=26, P=0.44$ ) (Fig. 5). 


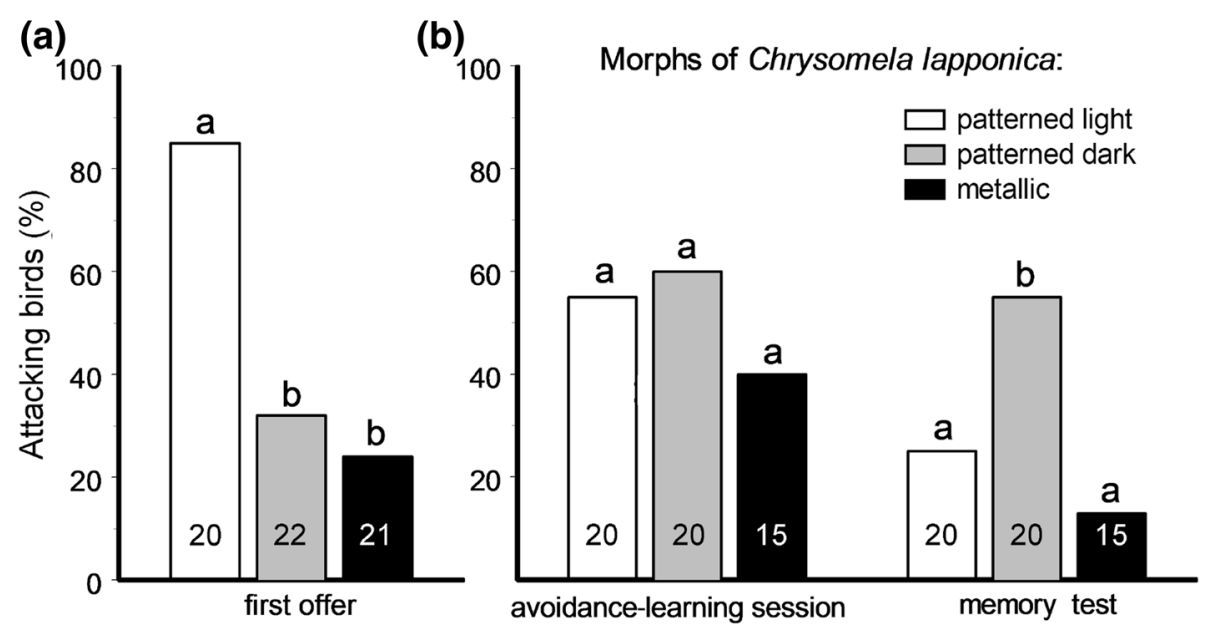

Fig. 3 Percentages of wild-caught great tits that attacked beetles of different colour morphs of Chrysomela lapponica in the first-offer trial (a) and percentages of birds that attacked a beetle in more than one trial during an avoidance-learning session and that attacked a beetle in a memory test carried out on the next day (b). The numbers

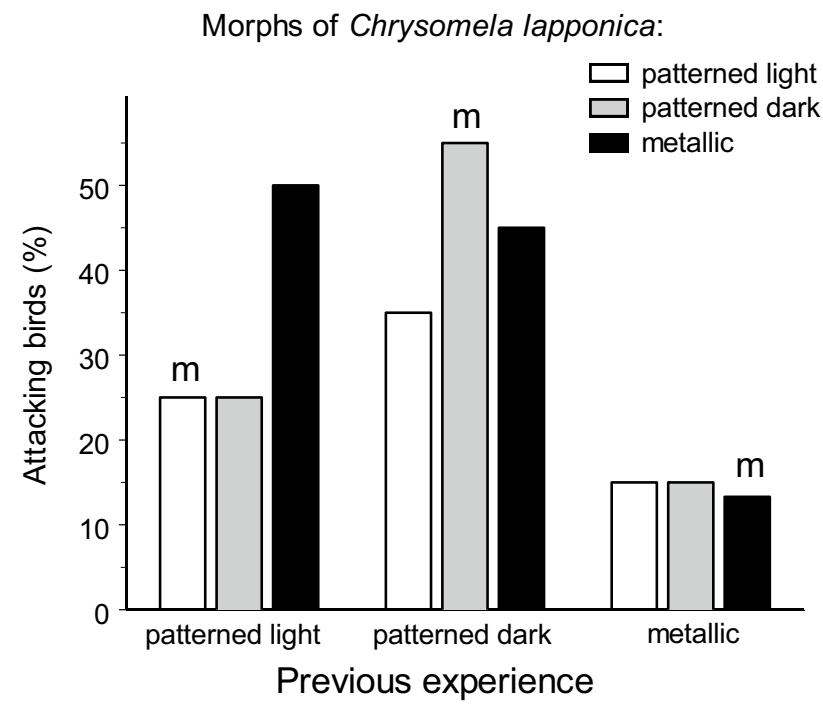

Fig. 4 Percentages of birds that attacked the three colour morphs of Chrysomela lapponica following experience with the same morph (memory test; bars marked by ' $\mathrm{m}$ ') or with a different morph (generalisation test). For sample sizes, consult Fig. 3; for statistics, consult the text

All naïve birds attacked at least one of the two offered beetles; therefore, the attack rate was significantly higher when compared with that of the wild-caught birds tested in a similar dual-choice test following their experience with $C$. lapponica (effect of experience, Fisher's exact test: $P<0.0001)$.

In total, $92 \%$ of offered beetles were attacked by juvenile birds. Neither the first choice (Fisher's exact test: $P=0.84$ of birds are shown within the bars; birds that did not attack any beetle were excluded from the avoidance-learning session and the memory test. Different letters indicate significant $(P<0.05)$ differences between colour morphs (Fisher's exact test)

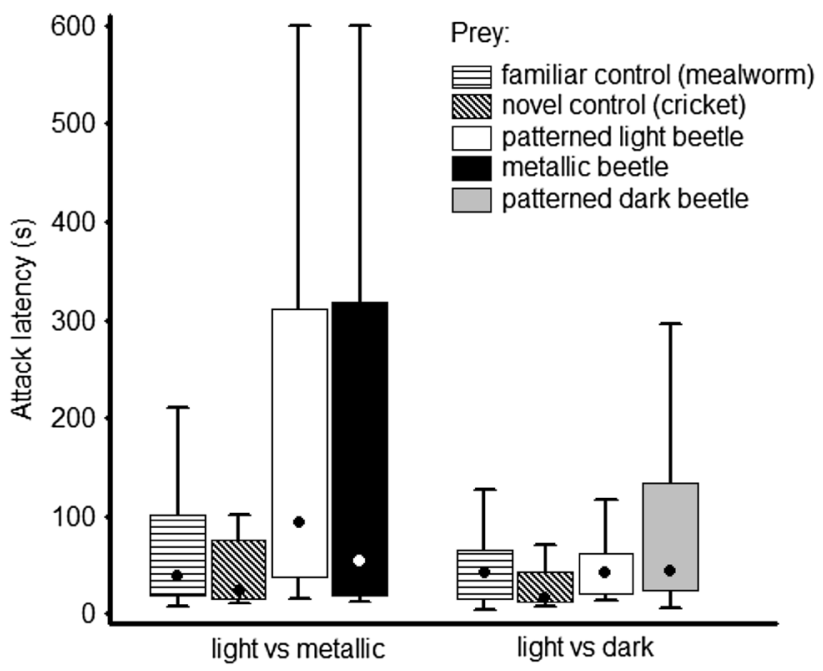

Fig. 5 First-attack latencies of hand-reared great tits towards different types of prey. Two groups of birds were given a choice between light patterned and metallic morphs ( 23 birds), or between light and dark patterned morphs ( 21 birds). Points indicate the median, boxes-lower and upper quartiles, whiskers-non-outlier range. All differences between prey types are non-significant $(P>0.05)$ (paired differences: Wilcoxon signed rank test; unpaired differences: Wilcoxon rank sum test)

and $P=0.51$ for birds selecting metallic vs light morphs and dark vs light morphs, respectively) nor beetle mortality $(P=1$ and $P=0.57$, respectively) depended on the colour morph of the beetles (Supplementary material Table 3). The proportion of attacked beetles that were subsequently killed by the birds did not differ between the colour morphs $(P=0.75$ and $P=0.20$ for birds selecting metallic vs light morphs and 
dark vs light morphs, respectively; Supplementary material Table 3). However, the birds tested with metallic vs light morphs approached the light beetles more frequently than they approached the metallic ones (Wilcoxon signed rank test: $V=33, P=0.03)$; the number of bird approaches per trial did not differ between the light and dark morphs $(V=22.5$, $P=0.30$ ) (Supplementary material Table 3 ).

Across all morphs, $44.4 \%$ of the beetles survived the attack by juvenile birds, and this value did not differ from the survival of beetles attacked by adult birds $(43.4 \% ; P=1)$. The percentage of beetles that were at least partly consumed by birds was also similar for both juvenile and adult birds (38.3 and $28.3 \%$, respectively; $P=0.19$ ) across all experiments.

Twenty-six of 44 birds demonstrated discomfort behaviour (mostly cleaning the bill) after attacking a beetle, but none of juvenile birds that consumed the beetle showed any symptoms of intoxication.

\section{Bird Predation on Colour Morphs of C. Iapponica in Field Experiments}

In the Kola Peninsula, birds damaged similar numbers of beetles in habitats with low and high densities of $C$. lapponica (34.3 and 30.0\%; Fisher's exact test: $P=0.72$ ). However, birds attacked beetles more intensively in sites with low density of $C$. lapponica when compared with high density sites (Kruskal-Wallis test: $\chi^{2}=4.36, \mathrm{df}=1$, $P=0.037$; Fig. 6). In low density sites, the attacks were more intensive on the light morphs than on the dark morphs (paired test: $t=2.54, \mathrm{df}=7, P=0.037$; Fig. 6 ),

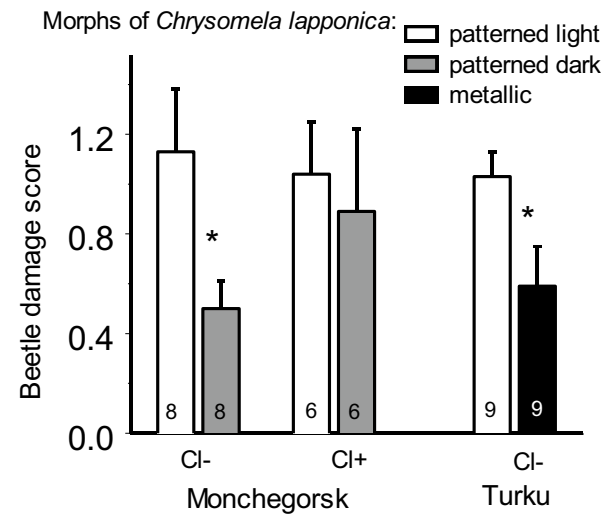

Fig. 6 Damage scores (mean $+\mathrm{SE}$ ) of different colour morphs of Chrysomela lapponica in field experiments in relation to the occurrence of local populations of $C$. lapponica (present: $\mathrm{Cl}^{+}$; absent, $\mathrm{Cl}^{-}$). Means are based on plant-specific values; numbers of plants are shown within the bars (plants where none of beetles was damaged by birds are excluded). Asterisks indicate significant $(P<0.05)$ differences between colour morphs (paired $t$-test) whereas in high density sites, the attack rates were similar for both morphs ( $t=0.66, \mathrm{df}=5, P=0.56$; Fig. 6).

In Turku, where $C$. lapponica did not occur, $48 \%$ of all beetles were damaged; and light beetles were damaged more frequently than metallic beetles $(t=2.82, \mathrm{df}=8$, $P=0.023$; Fig. 6).

\section{Discussion}

\section{Chemical Defence of C. Iapponica Against Bird Predators}

In our experiments, almost half of the attacked beetles were released unharmed, indicating that beetle chemical defence enhances individual survival upon predator attack. Moreover, only ca. $30 \%$ of the attacked beetles were eaten by great tits, confirming that these birds find $C$. lapponica beetles unpalatable. Thus, the chemical defence of $C$. lapponica appeared to be mostly based on taste rejection, and on irritating rather than on toxic effects, as indicated by the repeated bill cleaning by the birds after contact with beetle. Actual visible effects of poisoning were rare and weak. This mechanism of defence against birds is likely to be typical for many leaf beetle species of subtribe Chrysomelina, which share the same defensive chemicals (Pasteels et al. 1984).

Our findings support the conclusion by Skelhorn and Rowe (2009) that non-toxic, distasteful chemicals provide insect prey with effective protection against predators and increase the survival of individual prey through the taste-rejection behaviour by predators. Other experiments also showed that a considerable proportion of chemically defended prey can survive a predator attack (Wiklund and Järvi 1982; Sillén-Tullberg 1985; Hotová Svádová et al. 2013), and we confirmed that even naïve juvenile birds effectively assess the distastefulness of a prey. The higher degree of caution displayed by the wild-caught birds compared to hand-reared birds (indicated by lower rates of their first encounter attacks on the beetles) did not influence the rate of taste rejection. The high proportion of beetles that survived the bird attack adds to the evidence for the considerable importance of individual selection in the evolution of unpalatability. Therefore, we agree with Wiklund and Järvi (1982) regarding the overestimation of the importance of kin selection in the evolution of aposematic coloration as a result of the frequent use of dead prey or artificial items in the experiments and the assumption that all prey items are killed when attacked.

The absence of differences among colour morphs of C. lapponica in terms of their survival upon attack and in the probability of being eaten by the birds provides indirect evidence for a similarity in their defensive chemistry. Therefore, differences in bird reactions to colour morphs can be attributed to differences in the effects of the aposematic signal provided by prey coloration. 


\section{Bird Responses to Different Colour Morphs of $C$. Iapponica}

Great tits quickly learned to avoid beetles of all colour morphs: only half the birds that attacked the beetle repeated their attack upon encountering another beetle. This proportion did not differ among morphs, indicating that all studied types of beetle coloration elicit similarly fast avoidance learning; therefore all colorations function as effective warning signals. This result is in agreement with those of previous studies (Svádová et al. 2009; Ham et al. 2006) in which birds learned to avoid new prey of different colour morphs at the same rate.

Nevertheless, we detected some differences in the behaviour of great tits faced with beetles of different colours. For example, at the first encounter, wild-caught birds attacked light beetles at the same rate as they attacked a novel control prey, but they avoided dark and metallic beetles. C. lapponica was not found in the localities where the experimental birds were captured; therefore, the wild-caught birds used in our experiments could be considered naïve in relation to this beetle species. The responses of naïve birds to a novel prey may be considerably influenced by aposematic colours and patterns of the prey (Forsman and Merilaita 1999; Pegram and Rutowski 2014), but in our experiments, the hand-reared great tits attacked all morphs at the same rate and did not show any unlearned wariness of any of the morphs. Similarly, other studies found that naïve great tits showed no initial avoidance of warningly coloured prey (Exnerová et al. 2007; Hotová Svádová et al. 2013). Thus, the differences in the initial reactions of wild-caught birds to the colour morphs in our experiment cannot be explained by differences in unlearned wariness. More likely, the reactions of the wild-caught birds have been influenced by their previous experience with other prey species in nature (Exnerová et al. 2015).

Another difference between the studied beetle morphs concerns their memorability. In the memory test conducted a day after avoidance-learning session, many birds attacked the dark beetles again, whereas they continued to avoid light and metallic beetles. Similarly, Hegna et al. (2013) reported increased bird predation on more melanic individuals of wood tiger moth. These findings may indicate a lesser efficacy of the aposematic signal of a dark morph, which affects avoidance learning and memorability (Stevens and Ruxton 2012). This suggestion is supported by our observation that birds required more approaches and longer times for prey inspection at a closer distance to make a decision whether to attack or reject a dark beetle over beetles of the two other morphs. Importantly, the proportion of correct decisions (rejection after inspection) was similar for all morphs. Thus, the pattern of the dark morph cannot be identified by birds as an aposematic signal at greater distances.
The efficacy of an aposematic signal depends greatly on the pattern characteristics. For example, a contrasting internal pattern that includes several colour boundaries could increase the signal salience when compared to a pattern with few boundaries or the absence of a pattern (Aronsson and GamberaleStille 2013). The red-and-black pattern of the dark morphs of $C$. lapponica is less internally contrasting and has shorter colour boundaries (Fig. 1), which could make the warning signal of this morph less salient and therefore less memorable when compared with the pattern of the light morph. Moreover, smaller pattern elements are usually less effective than larger elements at enhancing avoidance learning in birds (Forsman and Merilaita 1999; Lindstedt et al. 2008). In our study, the pattern of the dark morphs of $C$. lapponica consisted of small red spots on a black background $(<15 \%$ of elytra area) whereas the pattern of the light morph consisted of larger red areas (30-50\% of elytra area). Consequently, the birds could readily recognise the pattern of the light beetles as aposematic from a longer distance. Moreover, the dark morph of $C$. lapponica is probably less conspicuous than the light morph, and at greater distances it may even be perceived as a camouflaged. Similar distance-dependent effects on birds have been demonstrated for other aposematic prey species (Gamberale-Stille et al. 2009; Barnett et al. 2017).

The combination of red and black elements is a textbook example of aposematic coloration (Endler and Mappes 2004), but the monotonous metallic colouration was as effective as light red-and-black pattern in our experiments in terms of predator avoidance learning and signal memorability. A metallic lustre is generally interpreted as a warning signal (Borer et al. 2010), but studies of bird responses to iridescence are scarce and the findings are contradictory: some, including our study, have demonstrated that iridescence itself enhances avoidance learning, (Fabricant et al. 2014; Waldron et al. 2017) while others have reported no effects of prey iridescence on bird attack rates (Pegram et al. 2015). This discrepancy may indicate that bird responses to iridescent coloration of prey are idiosyncratic.

\section{Generalization of C. Iapponica Colour Morphs by Bird Predators}

Our experiments revealed differences in the ability of the birds to generalise their experience with one colour morph of $C$. lapponica towards the others. The red-and-black pattern was generalised symmetrically between the light and dark morphs, so that learned avoidance of one morph resulted in avoidance of the other morph. This result is not surprising, keeping in mind the abilities of birds to generalise aposematic prey appearances (Aronsson and GamberaleStille 2013; Hotová-Svádová et al. 2013). Conversely, the generalisation between metallic and red-and-black morphs was clearly asymmetric. 
The attack rates were higher for the metallic than for the patterned beetles after a bird's experience with both light and dark morphs, indicating a limited generalisation of patterned coloration to metallic coloration. This may be explained by the considerable difference in aposematic signal characteristics: in the patterned morphs, the most important signal is formed by the red colour and internal contrasts, whereas in metallic morphs the most important signal is based on the structural coloration that produces the iridescent effect. Birds are likely to perceive these two types of signals quite differently, which makes their memorability more specific, although the protective value of both types of signals is similar. Birds that learned to avoid the metallic morph also avoided the two patterned morphs at the same rate, i.e. the birds were able to generalise a metallic coloration to a patterned coloration. The reason for this may be that when birds learned to avoid the intense iridescence of the metallic morphs, they subsequently avoided patterned morphs due to a metallic lustre of some parts of their bodies.

\section{Bird Predation on C. Iapponica Colour Morphs in Natural Habitats}

Light beetles were attacked more intensively than were dark beetles in the Kola Peninsula habitats with very low density of $C$. lapponica, where this prey species was mostly unfamiliar to the local bird community and where other species with similar coloration (e.g. ladybird Coccinella trifasciata) were extremely rare. This result corroborates the outcome of the laboratory experiment, where great tits, at the first encounter, attacked light beetles more frequently than dark beetles. We suggest that the reason behind the more frequent attacks on light $C$. lapponica beetles in the field is that they are more conspicuous than dark beetles. In particular, light morphs may be conspicuous to birds at greater distances, whereas dark morphs may not be perceived at long distances because of a distance-dependent camouflage effect (Stevens and Ruxton 2012). Consequently, when both types of coloration are novel for the birds, light beetles are attacked at a greater rate because their high conspicuousness increases the frequency of bird attacks on the novel aposematic prey (Mallet and Joron 1999). By contrast, in localities with abundant $C$. lapponica populations, where neither of the beetle morphs was novel for the birds, the conspicuousness of the light beetles increased the protective value of their warning signal by enhancing bird avoidance learning and prey memorability (Guilford 1986; Prudic et al. 2007).

Similarly, the higher conspicuousness of the red-and-black compared to the metallic coloration may explain the greater bird attack rates on light beetles than on metallic beetles in Finland. At the same time, we cannot exclude the possibility that avoidance of the metallic morph of $C$. lapponica is explained by the presence at our study site of other unpalatable species with iridescent coloration (e.g. Agelastica alni feeding on alder), which local birds had learned to avoid.

\section{Selection of Colour Morphs by Birds at Different Leaf Beetle Population Densities}

Thus, from field experiments, we suggest that, in Kola population of $C$. lapponica, the light beetles will have a survival advantage because avoidance learning is enhanced by their more frequent bird encounters and their higher conspicuousness when compared with dark beetles. This situation, in agreement with our theoretical expectations (Ruxton et al. 2004; Borer et al. 2010; Chouteau et al. 2016), could lead to a positive frequency-dependent selection. However, this process is observed only when the beetle density is high, so that most birds are experienced. By contrast, when most birds are naïve, either due to prevalence of juvenile birds or an extremely low beetle density, the high conspicuousness of light beetles will result in higher attack rates on individuals of this morph. Under these circumstances, we predict a negative frequency-dependent selection, potentially supporting polymorphism in the beetle population. Thus, the direction of frequency-dependent selection could change with the population density of polymorphic prey when the warning displays differ with respect to their conspicuousness to birds.

\section{Potential Consequences of Selective Bird Predation for Leaf Beetle Population Dynamics}

Changes in the colour morph frequencies associated with density fluctuations may have important consequences for population dynamics. According to Chitty's (1960) hypothesis, a variation in the selective survival of different phenotypes with prey density fluctuations may lead to self-induced population cycles (Krebs 1978; Saccheri and Hanski 2006). This emphasises the paramount importance of uncovering the mechanisms underlying density-dependent changes in the frequencies of $C$. lapponica morphs.

In an earlier study (Zvereva et al. 2002), we associated the differential survival of light and dark morphs of C. lapponica at different stages of population cycle with damage-induced changes in the host plant quality. Our current findings suggest that differential bird predation may also contribute to this variation and appears to act in the same direction as host plant quality. When beetle density is low, the frequency of the dark morph is significantly greater than it is in high density populations, presumably because the dark morphs are less conspicuous to birds. Conversely, after high-density years, when the birds have learned to avoid $C$. lapponica beetles, the frequency of dark morphs decreases, presumably because the dark pattern is less memorable for 
the birds. Thus, in prey populations with fluctuating density, the selection imposed by birds on the colour morphs may be directed differently during different stages of the population cycle (low density, density increase, high density and density decline), leading to cyclic variations in the morph frequencies.

\section{Conclusion}

Our laboratory experiments, in which live $C$. lapponica beetles were offered to great tits, showed that beetle colour morphs differed in their memorability and ability to elicit generalisation in the birds. Our field experiments showed that these differences influenced bird predation on different beetle morphs in nature, and that the relative survival of beetles with different patterns depended on the density of the $C$. lapponica population at the study site. We conclude that the direction of selective bird predation on prey that is polymorphic in its aposematic display is likely to vary with prey density: morphs with a less conspicuous display have a survival advantage at low population densities but they lose this advantage at high population densities. In combination with bottom-up factors, this selective predation is likely to influence variations in colour morph frequencies during population cycles and create feedback that can potentially contribute to the regulation of prey population dynamics.

Acknowledgements Open access funding provided by University of Turku (UTU) including Turku University Central Hospital. We are grateful to M. Hilker and Y. Mikhailov for sharing unpublished information with us. This work was supported by the Academy of Finland (project 268124), Czech Science Foundation (P505/11/1459) and Charles University research project (SVV 260434/2018).

\section{Compliance with Ethical Standards}

Conflict of interest The authors declare that they have no conflict of interest.

Ethical Approval We obtained permissions for experiments with wildcaught and hand-reared great tits from the Environmental Department of Municipality of Prague (S-MHMP-83637/2014/OZP-VII-3/R-8/F), Ministry of Agriculture (13060/2014-MZE-17214), and Ministry of the Environment of the Czech Republic (42521/ENV/14-2268/630/14). We ringed birds individually and released them back to the locality of capture within a few days after experimentation.

Open Access This article is distributed under the terms of the Creative Commons Attribution 4.0 International License (http://creativeco mmons.org/licenses/by/4.0/), which permits unrestricted use, distribution, and reproduction in any medium, provided you give appropriate credit to the original author(s) and the source, provide a link to the Creative Commons license, and indicate if changes were made.

\section{References}

Aronsson, M., \& Gamberale-Stille, G. (2013). Evidence of signaling benefits to contrasting internal color boundaries in warning coloration. Behavioral Ecology, 24(2), 349-354.

Barnett, J. B., Cuthill, I. C., \& Scott-Samuel, N. E. (2017). Distancedependent pattern blending can camouflage salient aposematic signals. Proceedings of the Royal Society of London B-Biological Sciences, 284(1858), 20170128.

Beatty, C. D., Beirinckx, K., \& Sherratt, T. N. (2004). The evolution of Müllerian mimicry in multispecies communities. Nature, 431(7004), 63-67.

Borer, M., van Noort, T., Rahier, M., \& Naisbit, R. E. (2010). Positive frequency-dependent selection on warning color in alpine leaf beetles. Evolution, 64(12), 3629-3633.

Brakefield, P. M., \& De Jong, P. W. (2011). A steep cline in ladybird melanism has decayed over 25 years: A genetic response to climate change? Heredity, 107(6), 574-578.

Broennimann, O., Ursenbacher, S., Meyer, A., Golay, P., Monney, J. C., Schmocker, H., Guisan, A., \& Dubey, S. (2014). Influence of climate on the presence of colour polymorphism in two montane reptile species. Biology Letters, 10, 20140638.

Chitty, D. (1960). Population processes in the vole and their relevance to general theory. Canadian Journal of Zoology, 38(1), 99-113.

Chouteau, M., Arias, M., \& Joron, M. (2016). Warning signals are under positive frequency-dependent selection in nature. Proceedings of the national Academy of Sciences, 113(8), 2164-2169.

Clusella-Trullas, S., Terblanche, J. S., Blackburn, T. M., \& Chown, S. L. (2008). Testing the thermal melanism hypothesis: A macrophysiological approach. Functional Ecology, 22(2), 232-238.

Cramp, S., \& Perrins, C. M. (1993). The birds of the Western Palearctic (Vol. 7). Oxford: Oxford University Press.

Dukas, R. (2002). Behavioural and ecological consequences of limited attention. Philosophical Transactions of the Royal Society B: Biological Sciences, 357(1427), 1539-1547.

Endler, J. A., \& Mappes, J. (2004). Predator mixes and the conspicuousness of aposematic signals. American Naturalist, 163(4), 532-547.

Exnerová, A., Ježová, D., Štys, P., Doktorovová, L., Rojas, B., \& Mappes, J. (2015). Different reactions to aposematic prey in 2 geographically distant populations of great tits. Behavioral Ecology, 26(5), 1361-1370.

Exnerová, A., Štys, P., Fučíková, E., Veselá, S., Svádová, K., Prokopová, M., et al. (2007). Avoidance of aposematic prey in European tits (Paridae): Learned or innate? Behavioral Ecology, 18(1), 148-156.

Fabricant, S. A., Exnerová, A., Ježová, D., \& Štys, P. (2014). Scared by shiny? The value of iridescence in aposematic signalling of the hibiscus harlequin bug. Animal Behaviour, 90, 315-325.

Forsman, A., \& Merilaita, S. (1999). Fearful symmetry: Pattern size and asymmetry affects aposematic signal efficacy. Evolutionary Ecology, 13(2), 131-140.

Gamberale-Stille, G. (2001). Benefit by contrast: An experiment with live aposematic prey. Behavioral Ecology, 12(6), 768-772.

Gamberale-Stille, G., Bragée, C., \& Tullberg, B. S. (2009). Higher survival of aposematic prey in close encounters with predators: An experimental study of detection distance. Animal Behaviour, 78(1), 111-116.

Gordon, S. P., Kokko, H., Rojas, B., Nokelainen, O., \& Mappes, J. (2015). Colour polymorphism torn apart by opposing positive frequency-dependent selection, yet maintained in space. Journal of Animal Ecology, 84(6), 1555-1564.

Gross, J., Schmolz, E., \& Hilker, M. (2004). Thermal adaptations of the leaf beetle Chrysomela lapponica (Coleoptera: Chrysomelidae) to different climes of Central and Northern Europe. Environmental Entomology, 33(4), 799-806. 
Guilford, T. (1986). How do" warning colours" work? Conspicuousness may reduce recognition errors in experienced predators. Animal Behaviour, 34, 286-288.

Ham, A. D., Ihalainen, E., Lindström, L., \& Mappes, J. (2006). Does colour matter? The importance of colour in avoidance learning, memorability and generalisation. Behavioral Ecology and Sociobiology, 60(4), 482-491.

Hegna, R. H., Nokelainen, O., Hegna, J. R., \& Mappes, J. (2013). To quiver or to shiver: Increased melanization benefits thermoregulation, but reduces warning signal efficacy in the wood tiger moth. Proceedings of the Royal Society of London B-Biological Sciences, 280(1755), 20122812.

Hotová Svádová, K., Exnerová, A., Kopečková, M., \& Štys, P. (2013). How do predators learn to recognize a mimetic complex: Experiments with naïve great tits and aposematic heteroptera. Ethology, 119(10), 814-830.

Joron, M., \& Mallet, J. L. (1998). Diversity in mimicry: Paradox or paradigm? Trends in Ecology \& Evolution, 13(11), 461-466.

Krebs, C. J. (1978). A review of the Chitty hypothesis of population regulation. Canadian Journal of Zoology, 56(12), 2463-2480.

Lindstedt, C., Eager, H., Ihalainen, E., Kahilainen, A., Stevens, M., \& Mappes, J. (2011). Direction and strength of selection by predators for the color of the aposematic wood tiger moth. Behavioral Ecology, 22(3), 580-587.

Lindstedt, C., Lindström, L., \& Mappes, J. (2008). Hairiness and warning colours as components of antipredator defence: Additive or interactive benefits? Animal Behaviour, 75(5), 1703-1713.

Lindstedt, C., Schroderus, E., Lindström, L., Mappes, T., \& Mappes, J. (2016). Evolutionary constraints of warning signals: A genetic trade-off between the efficacy of larval and adult warning coloration can maintain variation in signal expression. Evolution, $70(11), 2562-2572$.

Mallet, J., \& Joron, M. (1999). Evolution of diversity in warning color and mimicry: Polymorphisms, shifting balance, and speciation. Annual Review of Ecology and Systematics, 30(1), 201-233.

Mikhailov, Y. E. (2001). Significance of colour polymorphism in mountain populations of abundant leaf beetles (Coleoptera, Chrysomelidae). Pirineos, 156, 57-68.

Milyashevich, O. Y. (2000). Leaf beetles of genus Chrysomela L. Palaearctic fauna (species composition, biology and phenetic analysis of populations). Ph.D. dissertation, Byelorussian Institute for Plant Protection, Priluki, Byelorussia.

Nahrung, H. F., \& Allen, G. R. (2005). Maintenance of colour polymorphism in the leaf beetle Chrysophtharta agricola (Chapuis) (Coleoptera: Chrysomelidae: Paropsini). Journal of Natural History, 39(1), 79-90.

Nokelainen, O., Valkonen, J., Lindstedt, C., \& Mappes, J. (2014). Changes in predator community structure shifts the efficacy of two warning signals in Arctiid moths. Journal of Animal Ecology, 83(3), 598-605.

Pasteels, J. M., Rowell-Rahier, M., Braekman, J. C., \& Daloze, D. (1984). Chemical defences in leaf beetles and their larvae: The ecological, evolutionary and taxonomic significance. Biochemical Systematics and Ecology, 12(4), 395-406.

Pasteels, J. M., Rowell-Rahier, M., Braekman, J. C., Daloze, D., \& Duffey, S. (1989). Evolution of exocrine chemical defense in leaf beetles (Coleoptera: Chrysomelidae). Experientia, 45(3), 295-300.

Pauls, G., Becker, T., Rahfeld, P., Gretscher, R. R., Paetz, C., Pasteels, J., et al. (2016). Two defensive lines in juvenile leaf beetles; esters of 3-nitropropionic acid in the hemolymph and aposematic warning. Journal of Chemical Ecology, 42(3), 240-248.

Pegram, K. V., Han, H. A., \& Rutowski, R. L. (2015). Warning signal efficacy: Assessing the effects of color, iridescence, and time of day in the field. Ethology, 121(9), 861-873.
Pegram, K. V., \& Rutowski, R. L. (2014). Relative effectiveness of blue and orange warning colours in the contexts of innate avoidance, learning and generalization. Animal Behaviour, 92, 1-8.

Prudic, K. L., Skemp, A. K., \& Papaj, D. R. (2007). Aposematic coloration, luminance contrast, and the benefits of conspicuousness. Behavioral Ecology, 18(1), 41-46.

Punzalan, D., Rodd, F. H., \& Hughes, K. A. (2005). Perceptual processes and the maintenance of polymorphism through frequencydependent predation. Evolutionary Ecology, 19(3), 303-320.

Rojas, B., \& Endler, J. A. (2013). Sexual dimorphism and intra-populational colour pattern variation in the aposematic frog Dendrobates tinctorious. Evolutionary Ecology, 27(S1), 739-753.

Ruxton, G. D., Sherratt, T. N., \& Speed, M. P. (2004). Avoiding attack: The evolutionary ecology of crypsis, warning signals and mimicry. Oxford: Oxford University Press.

Saccheri, I., \& Hanski, I. (2006). Natural selection and population dynamics. Trends in Ecology \& Evolution, 21(6), 341-347.

Servedio, M. R. (2000). The effects of predator learning, forgetting, and recognition errors on the evolution of warning coloration. Evolution, 54(3), 751-763.

Sherratt, T. N. (2008). The evolution of Müllerian mimicry. Naturwissenschaften, 95(8), 681-695.

Sillén-Tullberg, B. (1985). Higher survival of an aposematic than of a cryptic form of a distasteful bug. Oecologia, 67(3), 411-415.

Skelhorn, J., \& Rowe, C. (2009). Distastefulness as an antipredator defence strategy. Animal Behaviour, 78(3), 761-766.

Stevens, M., \& Ruxton, G. D. (2012). Linking the evolution and form of warning coloration in nature. Proceedings of the Royal Society of London B-Biological Sciences, 279(1728), 417-426.

Sugeno, W., \& Matsuda, K. (2002). Adult secretions of four Japanese chrysomelinae (Coleoptera: Chrysomelidae). Applied Entomology and Zoology, 37(1), 191-197.

Svádová, K., Exnerová, A., Štys, P., Landová, E., Valenta, J., Fučíková, A., et al. (2009). Role of different colours of aposematic insects in learning, memory and generalization of naive bird predators. Animal Behaviour, 77(2), 327-336.

Svensson, E. I., \& Abbott, J. (2005). Evolutionary dynamics and population biology of a polymorphic insect. Journal of Evolutionary Biology, 18(6), 1503-1514.

Tullberg, B. S., Merilaita, S., \& Wiklund, C. (2005). Aposematism and crypsis combined as a result of distance dependence: Functional versatility of the colour pattern in the swallowtail butterfly larva. Proceedings of the Royal Society of London B: Biological Sciences, 272(1570), 1315-1321.

Waldron, S. J., Endler, J. A., Valkonen, J. K., Honma, A., Dobler, S., \& Mappes, J. (2017). Experimental evidence suggests that specular reflectance and glossy appearance help amplify warning signals. Scientific Reports, 7(1), 257.

Wang, S., Michaud, J. P., Runzhi, Z., Fan, Z., \& ShuAng, L. (2009). Seasonal cycles of assortative mating and reproductive behaviour in polymorphic populations of Harmonia axyridis in China. Ecological Entomology, 34(4), 483-494.

Wiklund, C., \& Järvi, T. (1982). Survival of distasteful insects after being attacked by naive birds: A reappraisal of the theory of aposematic coloration evolving through individual selection. Evolution, 36(5), 998-1002.

Zeuss, D., Brandl, R., Brändle, M., Rahbek, C., \& Brunzel, S. (2014). Global warming favours light-coloured insects in Europe. Nature Communications, 5, 3874.

Zverev, V., Kozlov, M. V., Forsman, A., \& Zvereva, E. L. (2018). Ambient temperatures differently influence colour morphs of the leaf beetle Chrysomela lapponica: Roles of thermal melanism and developmental plasticity. Journal of Thermal Biology, 74, 100-109.

Zvereva, E. L., Kozlov, M. V., \& Kruglova, O. Y. (2002). Colour polymorphism in relation to population dynamics of the leaf beetle, Chrysomela lapponica. Evolutionary Ecology, 16(6), 523-539. 